\title{
Epidermal inclusion cyst in a male breast: parallel linear echoes (tram-track appearance) on sonography as a diagnostic clue
}

\author{
Kumar Rahul, Ananya Panda, Nayha Handa, Smriti Hari
}

Department of Radiology, All India Institute of Medical Science, New Delhi, India

\section{Correspondence to}

Dr Nayha Handa,

nayhahanda@gmail.com

Accepted 14 October 2015

\section{DESCRIPTION}

A 25 -year-old man presented with a painless swelling in his left breast for 2 years. On palpation, the mass was soft and mobile. Mammography showed a high-density, circumscribed mass in the central breast (figure 1). Ultrasound showed a mass with multiple clusters of parallel alternating echogenic and hypoechoic lines resembling tram-tracks (figure 2). Colour Doppler did not reveal any flow. Biopsy yielded white flaky material. Pathology revealed this to be keratin flakes suggestive of an Epidermal Inclusion Cyst (figure 3).

This is an uncommon benign entity comprising of a cyst wall lined with stratified squamous epithelium and containing laminated keratin.

It is commonly located in the skin layer of the breast, but may also occur deep in the breast parenchyma.

Theories regarding the development of this cyst include traumatic implantation of epidermal fragments, squamous metaplasia in a dilated duct or inflammatory downgrowth of epidermis secondary to an obstructed hair follicle. ${ }^{1}$

These masses are well circumscribed, and isodense or of high density on mammography, with occasional benign calcifications. ${ }^{2}$

On ultrasound, the common appearance is a hypoechoic lesion with scattered echogenic foci while the most classical appearance is an onion ring appearance. The onion ring appearance comprises of alternating concentric hyperechoic and hypoechoic rings corresponding to lamellated keratin material. In our case, instead of the typical onion ring appearance, there were multiple parallel

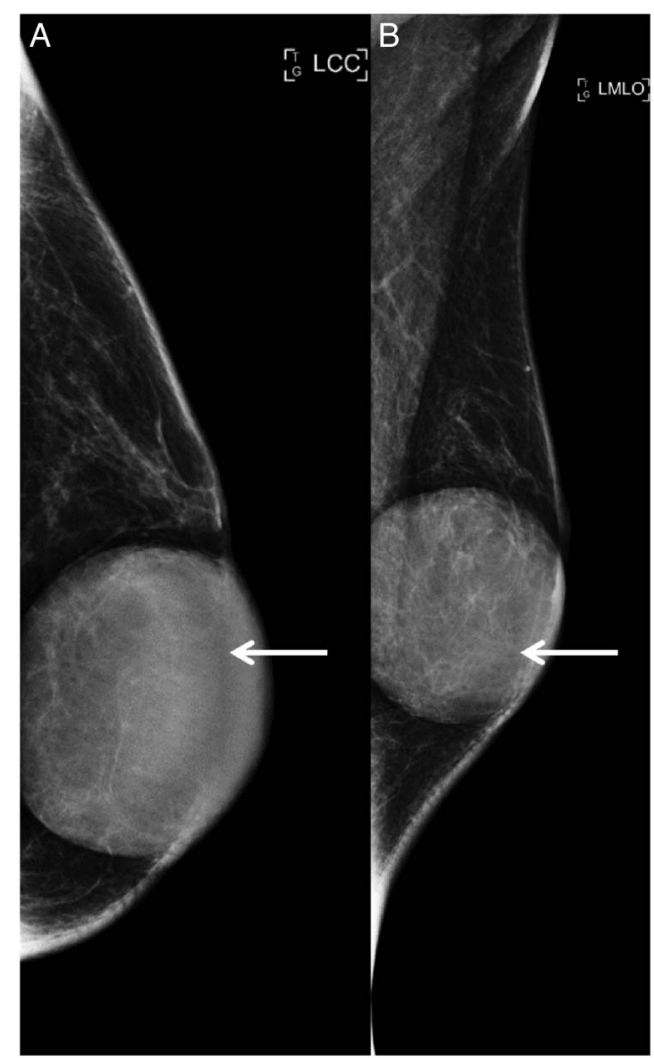

Figure 1 Digital mammogram craniocaudal (A) and mediolateral oblique (MLO) (B) views showing a round, circumscribed, high-density mass occupying the central inner breast parenchyma (arrow). The mass is extending from the skin and reaching the pectoralis major muscle on MLO view.
CrossMark

To cite: Rahul K, Panda A Handa $\mathrm{N}$, et al. BMJ Case Rep Published online: [please include Day Month Year] doi:10.1136/bcr-2015213045

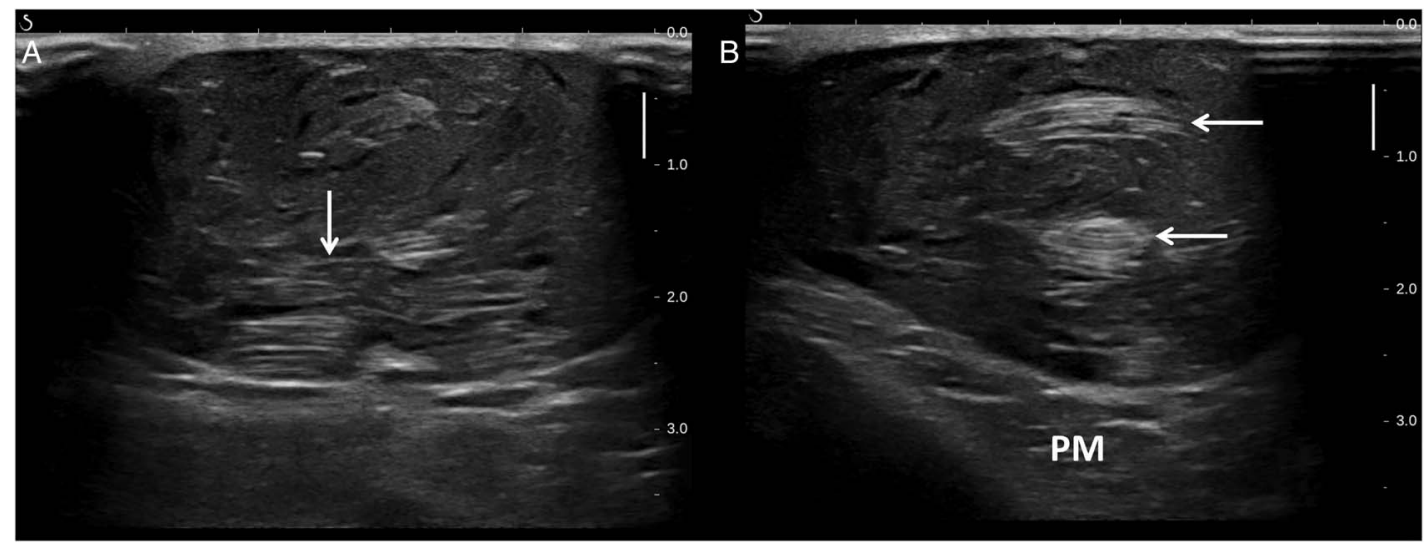

Figure 2 Ultrasonography transverse images (A and B) obtained with a $15 \mathrm{~Hz}$ high-frequency linear probe (Supersonic Aixplorer scanner) showing a well-encapsulated heteroechoic mass. The mass also showing multiple linear parallel alternating echogenic and hypoechoic lines (arrows) suggestive of a tram-track. 
Figure 3 (A) Photomicrograph showing cyst containing lamellated layers of keratin material filling up the cyst cavity (arrow, (A)) (H\&E $\times 100)$. (B) Photomicrograph at $\times 400$ magnification showing cyst lined by thin and stretched out squamous epithelium with presence of granular layer (blue colour). The granular layer can be seen abutting the lamellated keratin (arrow, (B)). No appendageal structures or abrupt keratinisation are seen.

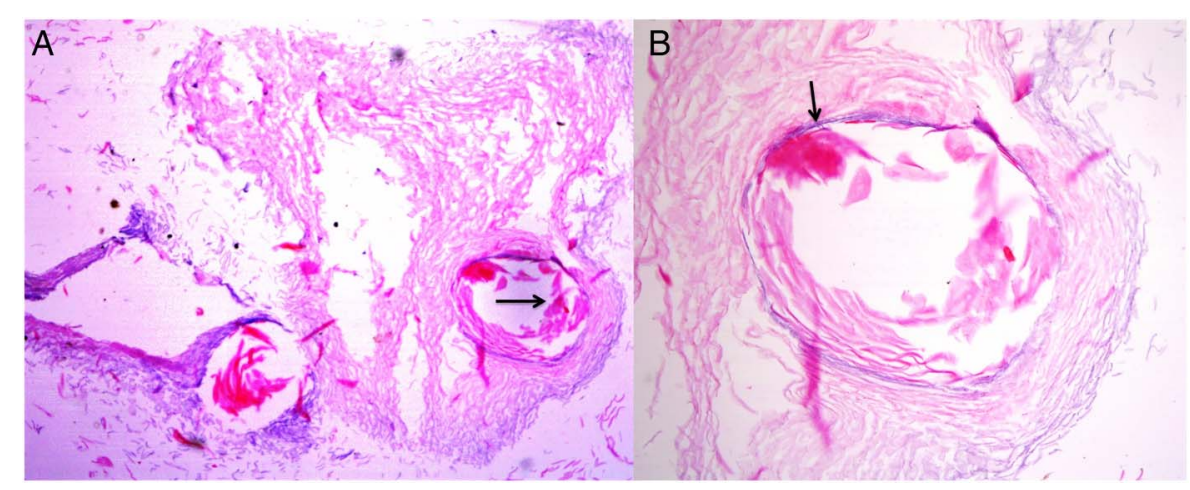

alternating hypoechoic and hyperechoic lines giving a tram-track appearance. $^{3}$

Asymptomatic, small and stable lesions do not require treatment. However, large or enlarging lesions have to be excised for cosmesis and to exclude an underlying malignancy.

\section{Learning points}

- An epidermal inclusion cyst is a dermal lesion in the breast. Diagnosis is relatively straightforward when the lesion is small, located in the dermis and associated with a history of trauma.

- However, in deep-seated lesions, ultrasound appearance of an epidermal inclusion cyst can be diagnostic and obviate the need for a biopsy.
Acknowledgements The authors would like to thank Dr Rakesh Deepak, Department of Pathology, All India Institute of Medical Sciences.

Competing interests None declared.

Patient consent Obtained.

Provenance and peer review Not commissioned; externally peer reviewed.

\section{REFERENCES}

1 Giess CS, Raza S, Birdwell RL. Distinguishing breast skin lesions from superficial breast parenchymal lesions: diagnostic criteria, imaging characteristics, and pitfalls. Radiographics 2011;31:1959-72.

2 Lam SY, Kasthoori JJ, Mun KS, et al. Epidermal inclusion cyst of the breast: a rare benign entity. Singapore Med J 2010;51:e191-4.

3 Crystal P, Shaco-Levy R. Concentric rings within a breast mass on sonography: lamellated keratin in an epidermal inclusion cyst. AJR Am J Roentgenol 2005;184(3 Suppl):S47-8.

Copyright 2015 BMJ Publishing Group. All rights reserved. For permission to reuse any of this content visit http://group.bmj.com/group/rights-licensing/permissions.

BMJ Case Report Fellows may re-use this article for personal use and teaching without any further permission.

Become a Fellow of BMJ Case Reports today and you can:

- Submit as many cases as you like

- Enjoy fast sympathetic peer review and rapid publication of accepted articles

- Access all the published articles

- Re-use any of the published material for personal use and teaching without further permission

For information on Institutional Fellowships contact consortiasales@bmjgroup.com

Visit casereports.bmj.com for more articles like this and to become a Fellow 